activities. Further, levels of public trust are affected by spillover effects from high or low levels of public trust in other parts of the government system. Last, many actors inside and outside the healthcare system influence public trust.

Conclusion Future research needs to translate this conceptual framework into policy guidelines, as well as to validate the conceptual framework for healthcare systems other than the British NHS.

\section{CONCEPTUALISING TRUST IN VIDEO CONSULTATIONS}

L Seuren*, S Shaw, C Pope, T Greenhalgh. University of Oxford, UK

\subsection{6/bmjopen-2021-QHRN.40}

Background Trust is recognised as an essential component of the patient-clinician relationship and high-quality care. With the turn to video consultations, patients and clinicians have raised concerns that it is harder to build and maintain trust. However, there is no research on how trust influences, and is influenced by, the video-mediated context.

Methods To investigate how trust matters for video consultations, we conducted a qualitative, in-depth study of the clinician-patient interaction in 37 video-recorded video consultations, drawn from 4 clinical settings (heart failure, diabetes, antenatal diabetes and cancer). We made detailed transcriptions and used Conversation Analysis to do a fine-grained analysis of the interaction, guided by the question 'how does trust play out in the video-mediated consultation and how does technology influence this?' Analysis of data occurred in parallel with development of theory.

Findings Our data support a new theorisation of trust in the video consultation, which can be conceptualised on three levels. First, trust in the technology itself: that it will function as expected (e.g., that both parties will be able to see and hear each other adequately). Second, trust that the other party will be able to use technology effectively to achieve the goals of the consultation (e.g., that the patient will be able to perform an examination). And third, the traditional trust of the therapeutic alliance (in which patients and clinicians build and maintain a working relationship), which may be supported or impeded by technology.

Discussion If video consultations are to become the 'new normal' for healthcare encounters, it is crucial that patients and clinicians are able to a) trust the technology, b) trust one another's capability to use the technology, and c) use the technology to build and maintain a therapeutic relationship. Further research should explore how to optimise these different kinds of trust.

\section{TRUTH AND TRUST IN CONSENT TO SURGERY}

P Alderson*, K Sutcliffe, R Mendizabal. Social Research Institute, UCL, UK

\subsection{6/bmjopen-2021-QHRN.41}

Truth and trust are at the centre of valid consent to surgery, with honest accounts and agreements by patients and surgeons. Yet social scientists' study of consent is complicated by their uneasy relationships with truth. Ethnographies can involve researchers' deceptions. Positivist truth claims rest on the findings being precisely replicable, which is not possible with unpredictable free agents in complex social contexts. Interpretivists' views of contingent truths can be relativist.

Critical realism helps to resolve these problems by combining the strengths of positivism and interpretivism within a larger framework. Like positivism, critical realism accepts that there is true reality, independent of our fallible thinking about it. Critical realists agree with interpretivists that there can be countless interpretations of reality, but not that these alter or construct reality itself. Critical realism understands everything at three levels.

The empirical level involves our experiencing, thinking and talking about reality. People may misinform, deliberately or in ignorance, leading to scepticism about whether truth exists.

The actual level involves existing things, people and events, offering stronger grounds for establishing truths. Yet appearances can be deceptive.

The third level is of real causal mechanisms, usually unseen by normal vision and only known in their effects, gravity for instance. Doctors' diagnoses rely beyond symptoms on causes, such as viruses or heart lesions. Social causal mechanisms include class, gender, (in)justice and trust.

Our research about consent, in two London children's heart surgery centres, illustrates the value of examining these three levels. Families and practitioners all held slightly differing viewpoints (the empirical level of interpretivism). These differing views all related to children's heart lesions and planned surgery (the actual positivist level). Valid consent also involves unseen voluntariness, courage and trust (the real causal motivating level). The three interacting levels are central to consent to surgery, and to social research.

\section{Day 2: Friday 19th March - 14.50-15.50}

\section{\begin{tabular}{|l|l}
4 & THE BUILDING OF EPISTEMIC TRUST: AN ADOPTIVE
\end{tabular} FAMILY'S EXPERIENCE OF MENTALIZATION BASED- THERAPY}

${ }^{1} \mathrm{~A}$ Jaffrani* ${ }^{*}{ }^{2} \mathrm{~T}$ Sunley, ${ }^{1} \mathrm{~N}$ Midgley. ${ }^{1}$ University College London, UK; ${ }^{2}$ Bristol University, UK

\subsection{6/bmjopen-2021-QHRN.42}

Background Recently, theorists have posited the development of epistemic trust - the trust in others as reliable sources of information - as an essential aspect of the therapeutic relationship and a mechanism of therapeutic change. Epistemic trust is likely to be disrupted in adoptive children and families and Mentalization Based Treatment (MBT) aims to explicitly promote its development.

Aim This study aims to investigate how epistemic mistrust is addressed and how epistemic trust is established within the MBT framework.

Methods This single-case, exploratory study reports data from in-depth interviews with one adoptive family, which were analyzed qualitatively using Interpretative Phenomenological Analysis.

Results Two superordinate themes are reported: pre-therapy factors contributing to epistemic mistrust and factors contributing to the development of epistemic trust. The findings highlight two critical elements in establishing epistemic trust: the use of certain clinical skills that help build a secure base within therapy and the possibility of trust being transferred from and to other professionals/systems beyond therapy. 
Conclusion This study informs a deeper understanding of how epistemic trust may be built in therapeutic work with adopted children and identifies possible clinical approaches that may be used by clinicians working with this client group.

\section{LINKED LIVES AND EVOLVING RELATIONSHIPS OF TRUST IN GENOMIC MEDICINE}

S Weller*, K Lyle, L Ballard, A Lucassen. University of Southampton, UK

10.1136/bmjopen-2021-QHRN.43

Background In areas of medicine such as genomics, understanding the experiences of an individual patient is insufficient because they are likely to have family members who may be directly affected by the outcome of a genomic test. Work in this field often focuses on the perspectives of health professionals, for example, in relation to how sharing 'results' might damage familial trust.

Aim To provide new knowledge about the ways in which existing relationships of (mis)trust within families shapes patient's willingness to discuss and share information with others.

Methods Taking a qualitative longitudinal approach, we documented the journeys of patients and their families as they experienced genomic testing to understand how, over time, the process impacts on their lives and relationships. The project forms part of a Wellcome Trust collaborative award focusing on the ethical and social challenges that arise for health professionals, patients and families, working and living with genomic results. Repeat in-depth interviews with patients and their families were conducted. The purposive sample was stratified by those affected by a rare disease or cancer. Situational and diachronic/longitudinal analysis were employed.

Results Drawing on the notion of linked lives from lifecourse research, we argue that patients' views on the sharing of genetic information needs to be explored in relation to the matrix of familial relationships of trust in which they are located (or detached). This enables a greater appreciation of how trust shapes and is shaped by the sharing/withholding of different aspects of the journey through genomic testing. Moreover, the ways in which different health professionals and their practices feature in these matrices at different points in patient's journeys is also salient.

Conclusions An understanding of the complexity of such trust relationships highlights how consent processes are often deficient in capturing the range of decisions that need to be made.

\section{Theme: Methodological innovations: exploring methods and concepts for exploring trust within research}

\section{Day 1: Thursday $18^{\text {th }}$ March $-13.35-14.55$}

\section{TRUST, LOCAL KNOWLEDGE AND LOCAL ACTION}

R Duncombe*, M Pawar. University of Queensland and Charles Sturt University, Australia
This paper discusses trust and relationship in a piece of practice research that investigated health service access for people living homeless in a rural coastal town. The research used conversations with two socially disparate groups of participants; people living homeless and people providing services.

As a long term resident, staff member of the Health Service and regular attendee of a Breakfast for people living homeless, my position as a social worker was both highly transparent, and socially located between the two groups of participants.

Both experiential and observational data was collected using an inclusive action research methodology.

Reflection on the social action and the qualitative data analysis show that working with a population living with significant vulnerability requires a researcher to be authentic and dependable to ensure their trust. Working with providers with significant time restraints requires a researcher to be organised and efficient. These characteristics are different elements of trust on which both the recruitment and conduct of this research was dependent. Trust was dependent on and arose from; trust in the Health Service, trust in the Breakfast and trust in the researcher personally.

The District Oral Health Service was subsequently able to act on the basis of this locally constructed knowledge to provide access to the public dentist using the strategy designed by the people living homeless themselves. Council also used the knowledge to contribute to a significantly reviewed policy for dealing with non-compliant campsites of those living homeless.

Based on these outcomes, the paper argues for the value of practice based, action-oriented research in small communities that draws on trust in local institutions and personnel. The process and outcome of this research has implications for inclusion in knowledge building as a powerful strategy for local action on national issues.

\section{MISTRUST IN ETHNOGRAPHY - SHOULD WE BE WORRIED ABOUT BETRAYING OUR RESEARCH SUBJECTS?}

P Pushkar. University of Manchester, UK

\subsection{6/bmjopen-2021-QHRN.45}

This article explores the analytical usefulness of mistrust in ethnographic research. I ground my argument through reference to my own fieldwork in which I did participant observation with political activists campaigning against cuts and privatisation in the NHS.

Engaging in relationships characterised by mistrust is unavoidable for most people and most ethnographers. I argue that although reflection on such engagements can be uncomfortable, they can shed light on what matters to researchers, namely, the nature of social relations.

Recent anthropological literature is increasingly rejecting previous conceptualisations of mistrust simply as the absence of trust. Mistrust is better theorised as a particular way of managing uncertainty in social relations. However, the recent literature on mistrust has not been applied to the relationship between researcher and subjects of research. 